\title{
Extending the use of dewatered alum sludge as a P-trapping material in effluent purification: Study on two separate water treatment sludges
}

\author{
Y.Q. $\mathrm{ZHAO}^{1} *$ and Y. YANG ${ }^{1,2}$
}

\author{
${ }^{1}$ Centre for Water Resources Research, School of Architecture, Landscape and Civil \\ Engineering, University College Dublin, Belfield, Dublin, Ireland \\ ${ }^{2}$ School of Environmental and Municipal Engineering, Xi' an University of Architecture and \\ Technology, Xi'an 710055, PR China
}

\footnotetext{
*Address correspondence to Y. Q. Zhao, Centre for Water Resources Research, School of Architecture, Landscape and Civil Engineering, Newstead Building, University College Dublin, Belfield, Dublin 4, Ireland; E-mail: yaqian.zhao@ucd.ie
}

\section{Abstract}

The generation of alum sludge from drinking water purification process remains inevitable when aluminium sulphate is used as primary coagulant for raw water coagulation. Sustainable managing such the sludge becomes an increasing concern in water industry. Its beneficial reuse is therefore highly desirable and has attracted considerable research efforts. In view of the novel development of alum sludge as a value-added raw material for beneficial reuse for wastewater treatment, this study examined the maximum phosphorus-adsorption capacity of two dewatered alum sludges sampled from two largest water treatment works in Dublin, Ireland. The objective lies in clarifying the change of alum sludge characteristics and its P-adsorption capacity over the location of the alum sludge produced and the raw water being treated. Experiments have demonstrated that the two alum 
sludges have the similar P adsorption capacity $(14.3 \mathrm{mg} \mathrm{P} / \mathrm{g}$ sludge for Ballymore-Eustace sludge and $13.1 \mathrm{mg} \mathrm{P} / \mathrm{g}$ sludge for Leixlip sludge at $\mathrm{pH}$ 7.0). However, the study supports that alum sludge beneficial reuse as a low cost adsorbent for P immobilization should study its P-adsorption capacity before any decision of large application is made since the raw water quality will affect the sludge characteristics and therefore influence its adsorption ability.

Keywords Adsorption; constructed wetland; dewatered alum sludge; phosphorus; reuse; wastewater treatment

\section{Introduction}

On the longer term, beneficial reuse in large scale of industrial wastes/by-products will help to promote the sustainable development. Effective management of the aluminium-coagulated drinking water treatment sludge (commonly termed as alum sludge) requires a sustainable approach that maximizes its value of reuse/recycle for other industrial demands and the environmental needs. Beneficial reuse of the alum sludge seems extremely desirable because it is an easily, locally and largely available by-product inevitably produced from water treatment works worldwide when aluminium sulphate is used as primary coagulant. In Ireland, 18,000 tonnes (dry solids) of alum sludge in an annual basis is generated with landfill disposal costs of about $€ 3.2$ million. In the UK, about 182,000 tonnes (dry solids) of waterworks sludge is generated each year, with disposal to landfill as the predominant disposal route. ${ }^{[1]}$ Researchers have worked for years to investigate the feasibility of various possible reuse of the alum sludge, but the major route of reuse lies in 
manufacturing and construction industries. ${ }^{[2]}$ The final disposal of the alum sludge is still focused on landfill with little known value of reuse. However, alum sludge is predominantly composed of amorphous aluminium hydroxide. It holds great promise for use as a valuable material or adsorbent in the treatment of wastewater since the aluminium can enhance adsorption and chemical precipitation processes to remove various pollutants, especially phosphorus (P). This is acknowledged from the principle of chemistry that aluminium ion has strong adsorption affinity with P. ${ }^{[3]}$

In the Centre for Water Resource Research, University College Dublin, Ireland, a research group has conducted extensive work to identify the characteristics and the P adsorption capacity of the locally generated alum sludge. It has been demonstrated that the dewatered alum sludge is a reliable and cost-effective material for P-rich wastewater treatment. ${ }^{[4-8]}$ This has provided valuable information regarding a beneficial reuse of the alum sludge in environmental and civil engineering. For example, a so-called novel engineered wetland system for high strength P-rich wastewater treatment has been developed by employing locally dewatered alum sludge as main substrate in the wetland system. ${ }^{[9]}$ This provides a good showcase of using "waste" for wastewater treatment. ${ }^{[1]}$

Although it has been demonstrated that alum sludge exhibited good $\mathrm{P}$ adsorption capacity, the capacity is affected by many factors, such as the nature of the alum sludge, which includes (i) the dosage of aluminium sulphate for coagulation and (ii) characteristics of the raw water being treated etc. In addition, these factors often vary from site to site and from year to year. Therefore results obtained from any study of alum sludge adsorption capacity for $\mathrm{P}$ immobilization are specific to the particular location and season. For these reasons results of $\mathrm{P}$ adsorption obtained from alum sludge adsorption trial in one location cannot be accurately extrapolated for different alum sludges in other locations across the country. Therefore, site- and sludge type-specific information for $\mathrm{P}$ adsorption 
should be obtained by performing controlled laboratory experiments.

Only in Dublin, there are four water treatment works (WTW) to supply drinking water to the city (Fig. 1). Ballymore-Eustace WTW (located in south Dublin) and Leixlip WTW (located in West Dublin) are the two major waterworks to provide drinking water service. This paper aims at examining $\mathrm{P}$ adsorption capacity onto alum sludge by sampling (in the same season) alum sludges derived from two separate WTW in Dublin. Characteristics and P adsorption capacity of the two kinds of alum sludges were examined in detail in a comparative manner. Thereafter, the application prospects of the alum sludge as main substrate in engineered treatment wetland system for P-rich wastewater treatment are also discussed.

\section{[Insert Fig. 1 here]}

\section{Materials and methods}

\section{Alum sludges and their characterization}

Dewatered alum sludge cakes of about $10 \mathrm{~kg}$ were collected respectively from the dewatering unit of the Ballymore-Eustace WTW (located in Co. Kildare, South Dublin) and Leixlip WTW (located in west Dublin) on the same day in May 2007 (Fig. 1). The former uses a nearby Poulaphuca reservoir water to produce $230,000 \mathrm{~m}^{3} / \mathrm{d}$ of potable water and the latter extracts the water from River Liffey. The alum sludge in Ballymore-Eustace WTW was the brownish-green residual derived from the treatment of a medium colour, medium turbidity, raw water that had been sourced from the Dublin and Wicklow mountains, which are upland catchments of peat over granite bedrock. The alum sludge in Leixlip WTW was the dark brown residue produced from the treatment of a medium colour, medium turbidity, raw water that had been sourced from the River Liffey, which is originated from the upland catchment of limestone bedrock. 
Both the waterworks use aluminium sulphate as coagulant with dosage of $40-65 \mathrm{mg} / \mathrm{L}$ for Ballymore WTW and 40-60 mg/L for Leixlip WTW, respectively, to treat raw waters via the conventional processes of coagulation/flocculation, sedimentation, filtration and disinfection. Currently, in both waterworks, alum sludges from sedimentation tank together with back washing stream from filtration tank were thickened and then conditioned with organic polymer of Magnafloc LT25 with dosage of $0.6-1.5 \mathrm{mg} / \mathrm{L}$ for Ballymore WTW and 0.2-1.0 mg/L for Leixlip WTW, respectively. Polymer conditioned sludges were then dewatered by filter press to produce sludge cakes for landfill as final disposal in both the waterworks.

The collected alum sludge cakes (with solids content of $23 \%$ for Ballymore WTW and $25 \%$ for Leixlip WTW, respectively) were air-dried and then ground and sieved to prepare the testing samples. The alum sludges were further oven dried at $103 \pm 2^{\circ} \mathrm{C}$ for examining their physical and chemical properties. Characterization of the sludges was conducted using an energy dispersive spectrometry (EDS, INCA Energy, Oxford Instruments, Oxfordshire, UK). The major elemental components of $\mathrm{Al}, \mathrm{Fe}, \mathrm{Ca}, \mathrm{Mg}, \mathrm{P}$ and $\mathrm{Si}$ of the sludges were obtained by using Inductively Coupled Plasma-Optical Emission Spectrum (ICP-OES, IRIS Intrepid II XSP, Thermo Elemental, Franklin, Massachusetts, USA) while the $\mathrm{Cu}, \mathrm{Zn}, \mathrm{Cd}$ and $\mathrm{Pb}$ were determined by using Inductively Coupled Plasma-Mass Spectrometry (ICP-MS, X series, Thermo Elemental, Franklin, Massachusetts, USA). TOC (total organic carbon) was measured by TOC-V $\mathrm{V}_{\mathrm{CSH}}$ (Shimadzu, Tokyo, Japan). The specific surface area of the sludge samples was determined by the SET/ $\mathrm{N}_{2}$-adsorption method.

\section{P-adsorption tests}

Series of batch adsorption experimental investigations were conducted on $\mathrm{P}$ adsorption behaviour coupled with the adsorption capacity of the dewatered alum sludge determined using the Langmuir isotherm. Its linear form is given in Eq. (1). 


$$
\frac{C_{e}}{q_{e}}=\frac{1}{Q_{0} b}+\frac{C_{e}}{Q_{0}}
$$

where $q_{\mathrm{e}}$ is defined as the adsorption capacity at equilibrium, (mg P/g), $b$ is a sorption constant related to $\mathrm{P}$ binding energy, $(\mathrm{L} / \mathrm{mg}), Q_{0}$ is the maximum adsorption capacity (mg P/g sludge) and $C_{\mathrm{e}}$ is the equilibrium $\mathrm{P}$ concentration $(\mathrm{mg} \mathrm{P} / \mathrm{L})$. The slope and the intercept of the plot of $\left(C_{\mathrm{e}} / q_{\mathrm{e}}\right)$ versus $C_{\text {e }}$ give the values of $Q_{0}$ and $b$.

The phosphorus aqueous solution used for batch adsorption tests were prepared by dissolving potassium dihydrogen phosphate (Riedel De Haen $\mathrm{KH}_{2} \mathrm{PO}_{4}$, AnalaR grade) in distilled water. The Langmuir adsorption isotherm was studied by a series of batch adsorption tests. Initially, different weight of prepared alum sludges (with diameter less than $0.063 \mathrm{~mm}$ ) ranging from $0.1 \mathrm{~g}$ to $0.5 \mathrm{~g}$ and $100 \mathrm{~mL}$ of prepared $\mathrm{P}$ solution (with initial $\mathrm{P}$ concentration of $100 \mathrm{mg} \mathrm{P} / \mathrm{L}$ ) were poured into $150 \mathrm{~mL}$ plastic bottles. Thereafter, the $\mathrm{pH}$ of the mixed suspensions were adjusted to $4.3,6.0,7.0$, 8.5 and 9.0, respectively, by adding $0.1 \mathrm{M}$ sulphuric acid and $0.01 \mathrm{M}$ sodium hydroxide. The mixed samples were then placed on a Stuart Orbital Shaker (SSL 1, Bibby Sterilin Ltd.) and agitated at $200 \mathrm{rpm}$ for 48 hours for equilibrium to be achieved. This equilibrium time has been determined in a previous study. ${ }^{[4]}$ After 48 hours, the samples were removed from the shaker and filtered using a 0.45 Millipore membrane filters to separate the solids from the liquid for $\mathrm{P}$ residual monitoring, which was conducted using the stannous chloride method $(4500-\mathrm{PD})^{[10]}$ via a Unicam Helios $\alpha$ spectrophotometer (Helios Alpha, Unicam Ltd., Cambridge, UK). Duplicable tests were applied for $\mathrm{P}$ adsorption tests and the results were very close. Therefore, the average value was reported in the paper.

\section{Results}

\section{Alum sludge characterization}


The energy dispersive spectrometry spectra of the sludges are shown in Fig. 2. The chemical components have been clearly identified and Table 1 lists each of them in mass percentage. As expected, the main metallic element presented in both the sludges was Al, which was $17 \%$ (in mass) in Ballymore-Eustace sludge and $22 \%$ in Leixlip sludge, respectively. The other principal chemical components were $\mathrm{Ca}, \mathrm{Fe}$ and $\mathrm{Si}$ and the amount was $<3 \%$ in mass for both the sludges. The metallic elements of $\mathrm{Cu}, \mathrm{Zn}, \mathrm{Cd}$ and $\mathrm{Pb}$ in both the sludges are extremely low. It is noted that both the sludges contained significant amount of organic matters including humic acid. The amount given in terms of TOC is $173 \mathrm{mg} / \mathrm{g}$-sludge for Ballymore-Eustace sludge and $118 \mathrm{mg} / \mathrm{g}$-sludge for Leixlip sludge, respectively. In addition, both the sludges contained inherent $\mathrm{P}$ especially for Leixlip sludge, given $\mathrm{P}$ of $4.2 \mathrm{mg} / \mathrm{g}$-sludge.

The results of the specific surface area of the sludges showed that the Ballymore-Eustace WTW sludge has specific surface area of $49.03 \mathrm{~m}^{2} / \mathrm{g}$-sludge, while the specific surface area of the Leixlip WTW sludge is $46.33 \mathrm{~m}^{2} / \mathrm{g}$-sludge.

\section{[Insert Fig. 2 here]}

\section{[Insert Table 1 here]}

\section{Maximum P-adsorption capacity}

The maximum P-adsorption capacity of the alum sludges studied is given in Table 2. It shows that the dewatered alum sludges possess excellent P-adsorption capability with P-adsorption favoured at lower $\mathrm{pH}$. The highest $\mathrm{P}$ adsorption capacity tested is $22.4 \mathrm{mg} \mathrm{P} / \mathrm{g}$ sludge (at $\mathrm{pH}=4.3$ ) for Ballymore-Eustace sludge and $20.1 \mathrm{mg} \mathrm{P} / \mathrm{g}$ sludge (at $\mathrm{pH}=4.3$ ) for Leixlip sludge, respectively. Comparatively, the Ballymore-Eustace sludge has higher adsorption capacity in the lower $\mathrm{pH}$ range than that of the Leixlip sludge despite its lower Al content (see Table 1). However, the Leixlip sludge exhibited higher P-adsorption capacity when the $\mathrm{pH}$ of the $\mathrm{P}$ solution exceeded 7.0. 


\section{Discussion}

Globally the water industry is estimated to be worth $€ 370 \mathrm{Bn}$ per annum. The Irish water industry is estimated to be worth $€ 1.5 \mathrm{Bn}$ per annum. There are strong drivers for continued growth and innovation in this industry due to the urbanization, population growth and economical development. In view of the water industry development, beneficial reuse of alum sludge is an emerged area in environmental sustainable research and application. Alum sludges derived from the two largest water treatment works in Dublin were studied for possible variability of their maximum Padsorption capacity, which may be linked with the sludge characteristics.

It is noted that, for the two alum sludges studied, there is no significant difference in maximum Padsorption capacity being observed (Table 2). As a whole, the two Irish dewatered alum sludges exhibited an excellent P-adsorption ability, which is capable to compare with other alum sludges produced in other places in the world ${ }^{[6,11,12]}$ and even other industrial by-products/materials used for P adsorption. ${ }^{[13,14]}$ However, Ballymore-Eustace sludge has high P-adsorption capacity (in acid environment) (Table 2) while its $\mathrm{Al}$ content is lower than that of Leixlip sludge (Table 1). This result seems to be hard to understand since the $\mathrm{P}$-adsorption depends largely on the $\mathrm{Al}$ content in the sludge via ligand exchange. ${ }^{[5]}$ Actually, it is noted from Table 1 that the $\mathrm{P}$ and Ca contents in Leixlip sludge are significantly higher than those in Ballymore-Eustace sludge. The high P, Ca content in Leixlip sludge may cause the low ability of P-adsorption as investigated previously by Yang et al. ${ }^{[5]}$ In addition, TOC content in Ballymore-Eustace sludge is obviously high compared with that in Leixlip sludge. The high TOC content may affect the $\mathrm{P}$ adsorption since the $\mathrm{P}$ adsorption by alum sludge is dominated by the significant amount of reactive functional groups, such as $-\mathrm{OH},-\mathrm{Cl},-\mathrm{SO}_{4}$ and humic substances in the sludge surface via the ligand exchange mechanism. ${ }^{[5]}$ Thus, it is reasonable to believe that the source water quality will affect the sludge 
characteristics and accordingly affect the P-adsorption capacity.

The surface area of the two sludges tested indicated that the Ballymore-Eustace sludge has large surface area, which is contribute to the high $\mathrm{P}$ adsorption capacity. In general, both the sludges have the surface areas, which are similar in order to that of $61-67 \mathrm{~m}^{2} / \mathrm{g}$ for water treatment sludge reported by Lee et al. ${ }^{[15]}$ It has been pointed out that Ballymore-Eustace sludge contains higher organics (TOC) than that of the Leixlip sludge. This is probably due to the nature of source water quality since the Ballymore-Eustace WTW uses reservoir water, which may contain higher amount of humic substances especially in summer period to promote the possible eutrophication. As such, it is reasonable to infer that the $\mathrm{P}$ adsorption capacity of Ballymore-Eustace sludge may be varied cross the season.

In view of the reuse of the sludges tested as low-cost adsorbents, it is essential that materials are considered as inert, rather than toxic material. The metallic elements of $\mathrm{Cu}, \mathrm{Zn}, \mathrm{Cd}$ and $\mathrm{Pb}$ in both the sludges are extremely low and several orders of magnitude below USEPA regulatory guidelines for toxic wastes. ${ }^{[16]}$ This reflects a lack of heavy metal contamination in the raw/source waters being treated and suggests that the sludges can be readily used as adsorbents. Bearing this in mind, to develop the alternative options regarding the alum sludge final disposal and beneficial reuse, application of dewatered alum sludge in constructed wetland for P-rich wastewater treatment has been proactively studied in University College Dublin, Ireland. As dewatered alum sludge can play the multi-role in constructed treatment wetland system as low cost adsorbent to enhance $\mathrm{P}$ immobilization and as carrier for biofilm attachment/development, the novel alum sludge-based constructed wetland system has been developed, which provides good promise to promote the pollutants treatment efficiencies to a high level. ${ }^{[1,9]}$ 


\section{Conclusions}

Dewatered alum sludge from two major water treatment works in Dublin, Ireland were sampled and tested for maximum P-adsorption capacity for the purpose of examining the possible variability of the P-adsorption ability. Although there is no significant change on maximum P-adsorption capacity (14.3mg P/g sludge for Ballymore-Eustace sludge and $13.1 \mathrm{mg} \mathrm{P} / \mathrm{g}$ sludge for Leixlip sludge at $\mathrm{pH}$ 7.0), the study supports that the raw water quality will affect the sludge characteristics and therefore influence its adsorption ability. As a result, alum sludge beneficial reuse as a low cost adsorbent for P immobilization should study its P-adsorption capacity before any decision of large application is made.

\section{Acknowledgement}

This paper is based on research funded by the Irish Environmental Protection Agency (projects grants no: 2005-ET-S-7-M3). Ballymore-Eustace Water Treatment Works and Leixlip Water Treatment Works are thanked for their kind assistance during the study.

\section{References}

[1] Babatunde, A.O.; Zhao, Y.Q. New low-cost wastewater treatment system pioneered in Ireland. Proceedings of the Institution of Civil Engineers-CIVIL ENGINEERING. 2009, 162(4), 148.

[2] Babatunde, A.O.; Zhao, Y.Q. Constructive approaches towards water treatment works sludge management: An international review of beneficial re-uses. Crit. Rev. Environ. Sci. Technol. 2007, 37, 129-164.

[3] Omoike, A.I.; Vanloon, G.W. Removal of phosphorus and organic matter removal by alum during wastewater treatment. Water Res. 1999, 33, 3617-3627.

[4] Yang, Y.; Tomlinson, D.; Kennedy, S.; Zhao, Y.Q. Dewatered alum sludge: A potential adsorbent 
for phosphorus removal. Water Sci. Technol. 2006, 54(5), 207-213.

257 [5] Yang, Y.; Zhao, Y.Q.; Babatunde, A.O.; Wang, L.; Ren, Y.X.; Han, Y. Characteristics and mechanisms of phosphate adsorption on dewatered alum sludge. Separ. Purif. Technol. 2006, 51, 193-200.

[6] Razali, M.; Zhao, Y.Q.; Bruen, M. Effectiveness of a drinking-water treatment sludge in removing different phosphorus species from aqueous solution. Separ. Purif. Technol. 2007, 55, 300-306 (2007)

[7] Zhao, Y.Q.; Razali, M.; Babatunde, A.O.; Yang, Y.; Bruen, M. Reuse of Aluminium-based water treatment sludge to immobilize a wide range of phosphorus contamination: Equilibrium study with different isotherm models. Separ. Sci. Technol. 2007, 42, 2705-2721.

[8] Babatunde, A.O.; Zhao, Y.Q.; Burke, A.M.; Morris, M.A.; Hanrahan, J.P. Characterization of aluminium-based water treatment residual for potential phosphorus removal in engineered wetlands. Environ. Pollu. 2009, 157, 2830-2836.

[9] Zhao, Y.Q.; Babatunde, A.O.; Zhao, X.H.; Li, W.C. Development of alum sludge-based constructed wetland: An innovative and cost-effective system for wastewater treatment. J. Environ. Sci. Health Pt. A. 2009, 44, 827-832.

[10] APHA. Standard methods for the examination of water and wastewater (18 ${ }^{\text {th }}$ Edition), American Public Health Association, 1992, Washington DC.

[11] Ippolito, J.A.; Barbarick, K.A.; Heil, D.M.; Chandler, J.P.; Redente, E.F. Phosphorus retention mechanisms of a water treatment residual. J. Environ. Qual. 2003, 32, 1857-1864.

[12] Makris, K.C.; Harris, W.G.; O'Connor, G.A.; Obreza, T.A.; Elliott, H.A. Physicochemical properties related to long-term phosphorus retention by drinking-water treatment residuals. Environ. Sci. Technol. 2005, 39, 4280-4289.

[13] Westholm, L.J. Substrates for phosphorus removal-potential benefits for on-site wastewater 
treatment. Water Res. 2006, 40, 23-36.

281 [14] Cui, L.; Zhu, X.; Ma, M.; Ouyang, Y.; Dong, M.; Zhu, W.; Luo, S. Phosphorus sorption capacities and physicochemical properties of nine substrate materials for constructed wetland. Arch Environ. Contam. Toxicol. 2008, 55, 210-217.

[15] Lee, C.E.; Yang, W.F.; Chiou, S.S. Utilization of water clarifier sludge for copper removal in a liquid fluidized-bed reactor. Journal of Hazardous materials, 2006, B129, 58-63.

[16] USEPA. The toxicity characteristic leaching procedure. US Code of Federal Regulations, $40^{\text {th }}$ edition, Part 261, Appendix II, Washington DC, USEPA. 1992. 
Table 1. The chemical components of the dewatered alum sludge (DAS)

\begin{tabular}{cccc}
\hline Chemical & Unit & Ballymore-Eustace sludge & Leixlip sludge \\
composition & & & \\
\hline $\mathrm{Al}$ & $\mathrm{mg} / \mathrm{g}$ DAS & 169.52 & 222.79 \\
$\mathrm{P}$ & $\mathrm{mg} / \mathrm{g}$ DAS & 0.582 & 4.156 \\
$\mathrm{Ca}$ & $\mathrm{mg} / \mathrm{g}$ DAS & 4.03 & 32.73 \\
$\mathrm{Fe}$ & $\mathrm{mg} / \mathrm{g}$ DAS & 6.65 & 6.59 \\
$\mathrm{Mg}$ & $\mathrm{mg} / \mathrm{g}$ DAS & 0.251 & 0.71 \\
$\mathrm{~Pb}$ & $\mathrm{mg} / \mathrm{g}$ DAS & 0.019 & 0.021 \\
$\mathrm{Cd}$ & $\mu \mathrm{g} / \mathrm{g}$ DAS & 0.51 & 0.53 \\
$\mathrm{Zn}$ & $\mathrm{mg} / \mathrm{g}$ DAS & 0.065 & 0.072 \\
$\mathrm{Cu}$ & $\mathrm{mg} / \mathrm{g}$ DAS & 0.069 & 0.039 \\
$\mathrm{Si}$ & $\mathrm{mg} / \mathrm{g}$ DAS & 3.11 & 6.54 \\
$\mathrm{TOC}$ & $\mathrm{mg}-\mathrm{C} / \mathrm{g}$ DAS & 172.6 & 117.8 \\
\hline
\end{tabular}


314 Table 2. The maximum P-adsorption capacity of the DAS studied

\begin{tabular}{ccc}
\hline $\begin{array}{c}\mathrm{pH} \text { of } \mathrm{P}- \\
\text { solution }\end{array}$ & Ballymore-Eustace sludge & Leixlip sludge \\
\hline 4.3 & 22.4 & $(\mathrm{mg}-\mathrm{P} / \mathrm{g}$ DAS $)$ \\
6.0 & 18.3 & 17.0 \\
7.0 & 14.3 & 13.1 \\
8.5 & 1.1 & 2.8 \\
9.0 & 0.9 & 1.6 \\
\hline
\end{tabular}


Figure caption:

330

331 Fig. 1 Geographic layout of water treatment works in Dublin, Ireland

332 Fig. 2 Energy dispersive spectrometry spectra of the alum sludges; Ballymore-Eustace WTW sludge (left) and Leixlip WTW sludge (right)

334

335

336

337

338

339

340 


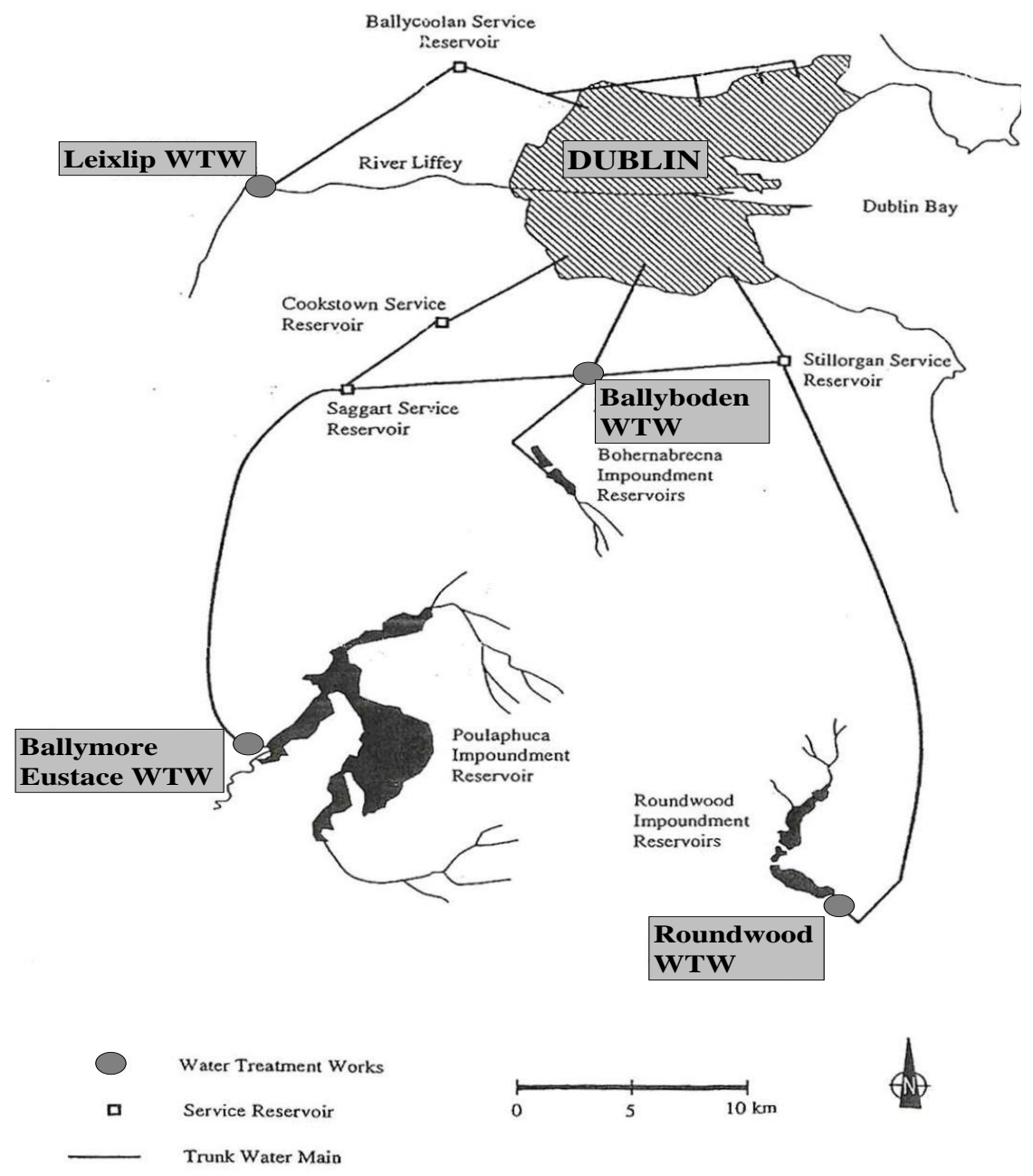




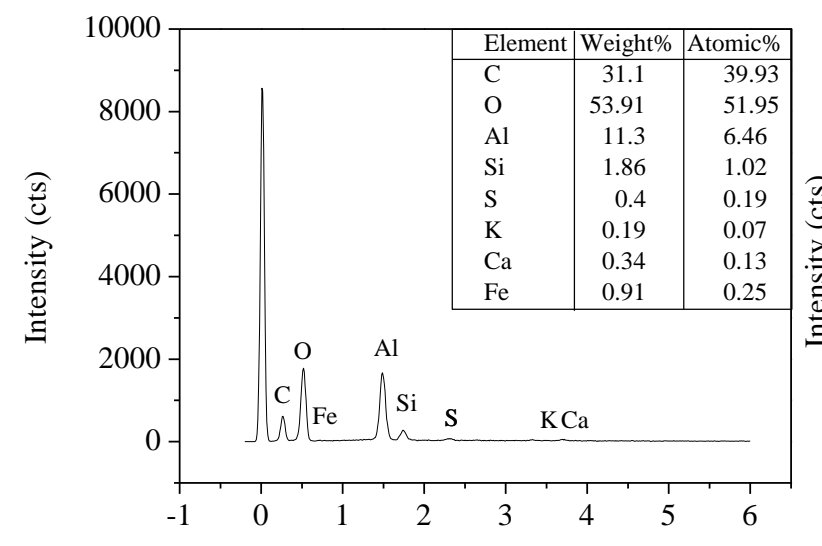

364 365 366 367 368

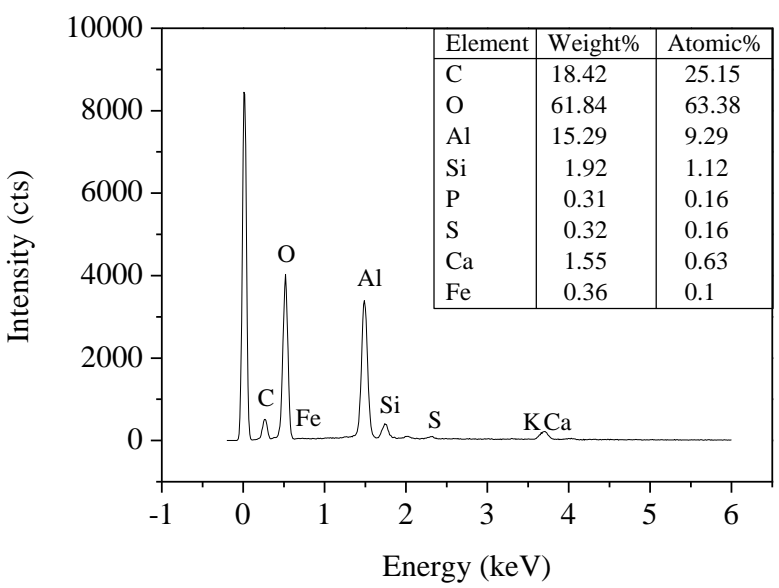

Fig. 2 